DOI: 10.12731/2658-6649-2019-11-5-26-31

УДК 612.017.1

\title{
ФЕНОТИП Т-ЛИМФОЦИТОВ ПРИ РАСПРОСТРАНЕННОМ ГНОЙНОМ ПЕРИТОНИТЕ В ЗАВИСИМОСТИ ОТ ИСХОДА
}

Беленюк В.Д., Мошев А.В.

С иелью исследования фенотипа Т-лимфочитов при распространенном гнойном перитоните (РГП) в зависимости от исхода заболевания обследовано 38 пачиентов в динамике лечения. При благоприятном исходе РГП в дооперационном периоде выявляется повышенное количество общих Т-лимфоцитов и $C D 4^{+}-T$-клеток, прежде всего за счет Treg. Независимо от исхода заболевания у больных значительно снижается содержание T-клеток, экспрессирующих CD28 и CD62L. При благоприятном исходе, к кониу наблюдения, повышается количество ијитотоксических T-лимфочитов и Т-клеток с экспрессией CD57.

Ключевые слова: перитонит; Т-лимфоциты; Т-регуляторные клетки; послеоперационный период; исход заболевания.

\section{PHENOTYPE T-LYMPHOCYTES WITH DISSEMINATED PURULENT PERITONITIS DEPENDING ON EXODUS}

\author{
Belenjuk V.D., Moshev A.V.
}

In order to study the phenotype of T-lymphocytes with disseminated purulent peritonitis $(R G P)$ in depending outcome of disease 38 patients were examined in the dynamics of treatment. With a favorable outcome of RGP in the preoperative period, an increased number of common T-lymphocytes and $C D 4^{+} T$-cells is detected, primarily due to Treg. Regardless of the outcome of the disease, the content of T-cells expressing CD28 and CD62L is significantly reduced in patients. With a favorable outcome, by the end of observation, the number of cytotoxic T-lymphocytes and T-cells increases with the expression of CD57.

Keywords: peritonitis; T-regulatory cells; postoperative period; outcome of the disease. 
По мнению большинства специалистов, одним из наиболее проблемных заболеваний абдоминальной хирургии является распространенный гнойный перитонит (РГП), летальность при котором может варьироваться в пределах от 10 до 30\%, а при генерализации воспаления и развитии полиорганной недостаточности достигать $80-90 \%$ [1, 2, 3]. Установлено, что тяжесть течения РГП, а так же характер и особенности развития различных сопутствующих осложнений, во многом зависят от изменений, происходящих в системе иммунитета $[4,5]$. В исследовании Wang W. et al. (2018) показано, что иммуноглобулинподобный муцин Т-клеток 3 (ТIM-3) является критическим отрицательным регулятором воспаления при перитонитах и является потенциальной мишенью для лечения заболеваний с неконтролируемой активацией воспаления [6]. Доказано, что Th17-лимфоциты стимулируют развитие противобактериального гуморального иммунитета при перитонитах [7]. Таким образом, целью нашего исследования была выбрана оценка фенотипического состава Т-лимфоцитов периферической крови у людей в динамике послеоперационного лечения в зависимости от исхода РГП.

\section{Материалы и методы}

На базе Краевой клинической больницы № 1 обследовано 38 пациента с острыми хирургическими заболеваниями осложнившимися РГП, в возрасте 25-65 лет. Из исследования были исключены пациенты, у которых причиной РГП являлись: острый деструктивный панкреатит, тотальный мезентериальный тромбоз, онкологические заболевания, туберкулез. Забор крови производили перед операцией, а также на 7, 14 и 21 сутки послеоперационного периода. В качестве контроля обследовано 40 относительно здоровых людей аналогичного возрастного диапазона. Исследование фенотипа Т-лимфоцитов крови проводили методом проточной цитометрии с моноклональными антителами (Beckman Coulter, USA). Пробоподготовку осуществляли по стандартной методике. Анализ окрашенных клеток проводили на проточном цитофлуориметре Navios, центра коллективного пользования КНЦ СО РАН.

\section{Результаты и обсуждение}

Функциональная активность Т-лимфоцитов значительно меняется у больных РГП в динамике послеоперационного периода, в том числе и в зависимости от исхода заболевания. Так, в дооперационном периоде при благоприятном исходе РГП выявляется повышенное количество Т-лимфо- 
цитов, которое в течение всего наблюдаемого послеоперационного периода снижается до уровня контрольных значений. При этом, у обследованных пациентов с неблагоприятным исходом РГП содержание Т-лимфоцитов в крови на всем протяжении обследования не изменяется и соответствует контрольному диапазону. У больных с благоприятным исходом заболевания в дооперационном периоде установлено превышение количества Т-лимфоцитов, экспрессирующих CD62L, на 21,3\% по сравнению с контрольными значениями и понижение их содержания к концу третьей недели послеоперационного периода в 1,3 раза. В то же время, при неблагоприятном исходе РГП обнаружен низкий уровень $\mathrm{CD} 62 \mathrm{~L}^{+}$-Т-клеток в дооперационном периоде и на 21-е сутки послеоперационного лечения. Обнаружены изменения в содержании цитотоксических T-клеток и $\mathrm{CD} 4^{+}$-T-лимфоцитов у больных в зависимости от исхода РГП. Так, только у пациентов с благоприятным исходом РГП к концу наблюдаемого периода послеоперационного лечения повышается количество цитотоксических Т-лимфоцитов (на 21 сутки) и активированных цитотоксических Т-клеток (с 14 суток). У больных с неблагоприятным исходом РГП количество цитотоксических Т-лимфоцитов в крови (включая активированные) и в до-, и в послеоперационном периоде соответствует контрольным значениям. В дооперационном периоде при благоприятном исходе заболевания выявляется повышение количества $\mathrm{CD} 4^{+}$-Т-лимфоцитов, однако к 21 -м суткам послеоперационного лечения наблюдается снижение уровня Т-хелперов у лиц данной группы. При неблагоприятном исходе РГП наблюдается только понижение содержания Т-хелперов к концу наблюдаемого периода. В то же время, повышенное в дооперационном периоде количество активированных CD4+-T-лимфоцитов (экспрессирующих CD62L) при благоприятном исходе РГП остается увеличенным в течение 14 дней послеоперационного лечения, тогда как при неблагоприятном исходе заболевания изменений в уровне активированных Т-хелперов в течение всего наблюдаемого периода не обнаружено. Важную роль в развитии иммуновоспалительных процессов играют Т-регуляторные клетки (Treg). При исследовании Treg и активированных Treg (с экспрессией CD62L, CD62L ${ }^{+}$-Treg) обнаружено, что при благоприятном исходе РГП выявляется увеличение количества Treg и CD62L $\mathrm{L}^{+}$-Treg в дооперационном периоде, сохранение повышенного уровня в начале послеоперационного лечения и понижение содержания на 21-е сутки наблюдаемого периода. При неблагоприятном исходе заболевания обнаружено снижение содержания Treg и CD62L $\mathrm{L}^{+}$Treg в дооперационном периоде и на 21-е сутки послеоперационного лечения. В целом, можно заключить, 
что динамика фенотипического состава Т-лимфоцитов в крови у больных РГП в до- и послеоперационном периоде имеет выраженные особенности в зависимости от исхода заболевания. При благоприятном исходе РГП наблюдается более выраженные изменения фенотипа Т-клеток в дооперационном периоде (повышение количества Т-лимфоцитов, Т-хелперов и Treg, включая клетки экспрессирующие CD62L), тогда как при неблагоприятном исходе РГП в указанный период выявляется снижение содержания CD62L $\mathrm{L}^{+}$-T-лимфоцитов, Treg и CD62L $\mathrm{L}^{+}$-Treg. Можно предположить, что именно недостаточность (функциональная и количественная) Treg и приводит к неконтролируемой активности воспалительных процессов при РГП и, соответственно, повышает вероятность неблагоприятного исхода заболевания. В конце послеоперационного лечения наблюдается снижение количества некоторых субпопуляций Т-лимфоцитов (например, Т-хелперов). Такая особенность динамики фенотипического состава Т-лимфоцитов уже слабее зависит от исхода заболевания и, по-видимому, в большей степени определяется применением антибиотиков и миграцией Т-клеток в зону воспаления. В частности, повышение содержания у больных с благоприятным исходом РГП Т-лимфоцитов, экспрессирующих CD57, также может быть связано применением антибиотиков в динамике послеоперационного периода.

\section{Заключение}

Фенотип Т-лимфоцитов крови у больных РГП в до- и послеоперационном периоде значительно различается в зависимости от исхода заболевания. При благоприятном исходе РГП в дооперационном периоде выявляется повышенное количество общих Т-лимфоцитов, в том числе, с экспрессией CD62L, а также CD4+-T-клеток, прежде всего за счет Treg (включая активированные клетки). Следовательно, повышение количества в крови Treg у больных РГП на пике заболевания является прогностическим признаком благоприятного исхода. Treg регулируют интенсивность воспалительного процесса, что приводит к улучшению клинического состояния больных РГП и, соответственно, повышает вероятность благоприятного исхода заболевания. Фенотип Т-лимфоцитов крови значительно меняется в динамике послеоперационного лечения. Независимо от исхода заболевания у больных значительно снижается содержание Т-клеток, экспрессирующих CD28 и CD62L, а также уровень T-хелперов и Treg. Только при благоприятном исходе заболевания к концу наблюдаемого периода (21 сутки лечения) в крови повышается количество цитотоксических Т-лим- 
фоцитов и Т-клеток с экспрессией CD57. Данные изменения фенотипического состава Т-лимфоцитов определяются применением антибиотиков и миграцией клеток в зону воспаления. Установленные особенности фенотипа Т-лимфоцитов в крови у больных РГП в дооперационном периоде и в динамике послеоперационного лечения определяют необходимость разработки методов иммуноактивной терапии для успешного лечения заболевания.

\section{Список литературы / References}

1. Ding W., Wang K., Liu B., Fan X., Wang S., Cao J., Wu X., Li J. Open Abdomen Improves Survival in Patients With Peritonitis Secondary to Acute Superior Mesenteric Artery Occlusion. J. Clin. Gastroenterol. 2017, 51(9), e77-e82.

2. Obi Y., Streja E., Mehrotra R., Rivara M.B., Rhee C.M., Soohoo M., Gillen D.L., Lau W.L., Kovesdy C.P., Kalantar-Zadeh K. Impact of Obesity on Modality Longevity, Residual Kidney Function, Peritonitis, and Survival Among Incident Peritoneal Dialysis Patients. Am. J. Kidney Dis. 2018, 71(6), 802-813.

3. Mai M., Stengel S., Al-Herwi E., Peter J., Schmidt C., Rubio I., Stallmach A., Bruns T. Genetic variants of TRAF6 modulate peritoneal immunity and the risk of spontaneous bacterial peritonitis in cirrhosis: A combined prospective-retrospective study. Sci. Rep. 2017, 7(1), 4914.

4. Mousa N., Besheer T., Abdel-Razik A., Hamed M., Deiab A.G., Sheta T., Eldars W. Can combined blood neutrophil to lymphocyte ratio and C-reactive protein be used for diagnosis of spontaneous bacterial peritonitis? Br. J. Biomed. Sci. 2018, 75(2), 71-75.

5. Cullaro G., Kim G., Pereira M.R., Brown R.S. Jr., Verna E.C. Ascites Neutrophil Gelatinase-Associated Lipocalin Identifies Spontaneous Bacterial Peritonitis and Predicts Mortality in Hospitalized Patients with Cirrhosis. Dig. Dis. Sci. 2017, 62(12), 3487-3494.

6. Wang W., Shi Q., Dou S., Li G., Shi X., Jiang X., Wang Z., Yu D., Chen G., Wang R., Xiao H., Hou C., Feng J., Shen B., Ma Y., Han G. Negative regulation of Nod-like receptor protein 3 inflammasome activation by $\mathrm{T}$ cell Ig mucin-3 protects against peritonitis. Immunology 2018, 153(1), 71-83.

7. Yu W., Yao D., Yu S., Wang X., Li X., Wang M., Liu S., Feng Z., Chen X., Li W., Wang L., Liu W., Ma J., Yu L., Tong C., Song B., Cui Y. Protective humoral and CD4(+) T cellular immune responses of Staphylococcus aureus vaccine MntC in a murine peritonitis model. Sci. Rep. 2018, 8(1), 3580. 


\section{ДАННЫЕ ОБ АВТОРАХ}

Беленюк Василий Дмитриевич, м.н.с.

Лаборатория клеточно-молекулярной физиологии и патологии ФГБНУ Федеральный исследовательский иентр «Красноярский научный центр Сибирского отделения Российской академии наук», обособленное подразделение «НИИ медиџинских проблем Севера» ул. Партизана Железняка, 32, г. Красноярск, 660022, Российская Федерациия

Мошев Антон Викторович, м.н.с., лаборатория клеточно-молекулярной физиологии и патологии ФГБНУ Федеральный исследовательский центр «Красноярский научный иентр Сибирского отделения Российской академии наук», обособленное подразделение «НИИ медиџинских проблем Севера» ул. Партизана Железняка, 32, г. Красноярск, 660022, Российская Федераиия

\section{DATA ABOUT THE AUTHORS}

Belenjuk Vasilij Dmitrievich, Junior Researcher, Laboratory of the Cellular Molecular Physiology and Pathology

Federal Research Center "Krasnoyarsk Science Center» of the Siberian Branch of the Russian Academy of Sciences, Scientific Research Institute of medical problems of the North

3g, Partizan Zheleznyak Str., 660022, Krasnoyarsk, Russian Federation

Moshev Anton Viktorovich, Junior Researcher, Laboratory of the Cellular Molecular Physiology and Pathology

Federal Research Center "Krasnoyarsk Science Center» of the Siberian Branch of the Russian Academy of Sciences, Scientific Research Institute of medical problems of the North

3g, Partizan Zheleznyak Str., 660022, Krasnoyarsk, Russian Federation 